\title{
THE DENTAL HYGIENIST-HER FIELD AND LIMITATIONS
}

\author{
By ALBERT H. STEVENSON,* D.D.S., New York City
}

(Read by C. N. Johnson, D.D.S., Chicago, Illinois, before the National Dental Association, Boston, Massachusetts, August 23-27, 1920)

$\mathrm{D}$ ENTISTRY is now passing thru the most critical period of its history. With the responsibility for apical foci of infection laid at its door, as well as for the harmful effects of those types of restorations so assailed by Hunter and others, it has been necessary to perfect old methods and to initiate new ones to meet the needs of the present day. The average practitioner, having sensed this responsibility, is so burdened with the necessary readjustments of his methods that the very thought of the duties incidental to preventive work quite overwhelms him. And yet preventive measures cannot be neglected. We have educated the public to a respect for the oral cavity. How then can we be consistent and still be remiss in applying all available means of prevention in our private practices?

We are called upon to deal with the most common of physical defects. And conservative estimates place the number of carious teeth in the United States at four hundred million. We have had but little help from the dietitian, since he has not as yet completely solved the problem of calcium deficiency and the foods required to meet this deficiency. With the increase in the use of free sugar (the present consumption per capita in the United Stal:s is one hundred pounds per year), we must be prepared for an. increase rather than a diminution in the

*Deceased. prevalence of dental caries, according to accepted views.

In fulfilling the obligations of his calling, the average practitioner is the oral physician as well as a prosthodontist, and as such has his time fully occupied. He is seldom looked upon as a preventer of dental lesions, and yet this should be his enviable distinction. That he consign a portion of the work to a trained assistant is a secondary consideration. The fact remains that it is his obligation and his responsibility to see that preventive treatment is given.

The value of periodic prophylactic treatment in destroying bacterial plaques on the surface of the teeth is substantiated by latest research and investigation. After agglutination, the plaque is so tenacious as to resist removal by the most persistent use of toothbrush and dentifrice by the patient, and being usually invisible is not detected until decalcification of the enamel has occurred and the initial lesion presents. Even this stage often remains undiscovered, and it is not until the incipient cavity is in evidence that dental relief is sought. Intelligent use of the porte polisher will materially reduce this in the normal mouth. The periodical removal of the plaques is a preventive measure of prime importance.

It is with a false sense of security that the inconsiderate dentist disregards this important service. In addition to the infective material from mucosa plaques, 
desquamation of a more or less abnormal mucosa itself, with its accompanying debris, contributes to the pollution of the stomach and intestines.

The average mouth presenting for treatment to the oral surgeon or to the orthodontist (to say nothing of the general practitioner) is usually unfit for his ministrations. Incrustations of salivary calculus containing decomposing food, dead bacteria as well as living organisms in active proliferation, are present. To operate in such a mouth is to violate the laws of asepsis, and to prepare a cavity or even to take an impression under these conditions indicates a disregard for the health of the patient. The salivary deposits should be removed with the accompanying debris-in short, the field of operation should be properly prepared. This the dental hygienist can and should do. It is a procedure entirely consistent with and contributing to the dignity of the dentists' efforts and is -... comparable to the preparation of the field of operation for a general surgeon by his medical nurse. The licensed medical nurse has long been permitted to do this and no one has expressed the fear that some day, with the increasing number of votes by women, she will seek legal permission to take the scalpel in her own hand.

The dental hygienist is the sanitary - aide of the dentist and can assume the duties without imperiling legitimate dental practice. On the contrary she will become as invaluable as those aides of the general surgeon-the pharmacist, the dietary expert, or the medical nurse.

Most state laws limit the work of the hygienist to the "removal of stains and accretions from the exposed surface of the teeth" or "under the free margin of the gum." Why should we be so fearful? Because in her perfectly legal perambulations she approaches the sacred gingiva? As a practicing periodontist, I yield second place to no man in my respect for the investing tissues of the teeth. But with all logic and consistency,
I ask does the dental hygienist endanger the profession of dentistry because the perfectly hygienic operation of removing calcareous deposits and debris has a beneficial effect upon the periodontium?

From the very first, the student trained to become a dental hygienist has had impressed upon her that "her efforts should be limited to the plus side of the oral health line." She is told that she should not treat pathological conditions. I anticipate the question, "What is to prevent her from yielding to an impulse to investigate pyorrhea pockets, curette roots and otherwise infringe upon the province of the periodontist?" The answer is obvious.

Train her in the use of instruments designed for use within her field and educate her to a professional respect for those tissues beyond her province. This is being done at Columbia University and in other schools.

The possibilities of the porte polisher with wood points and abrasive and polishing agents are not appreciated by the average dentist. When properly used, this implement is more thoro than any device attached to the dental engine, and will reach points not accessible to any other prophylactic instrument. To obtain the best results with the porte polisher, considerable force must be applied to the enamel surfaces. The dental hygienist is trained in a technic that develops the capacity to make intelligent use of this force and a high degree of manual dexterity. She is taught this technic upon manikins before working upon patients. Polishing tape is used on all interproximal surfaces.

Education.-It would be most unfortunate for the cause of oral hygiene, as well as for dentistry, if these voung women were poorly train $\mathrm{d}$ and inadequately equipped for the service they are called upon to give: The standards for her education must be beyond criticism. Her course of study is in a state of evolution and deserves earnest consideration by all those experienced in dental 
education. The course which she is required to traverse should be in harmony with the dental course and should meet the demands of all those interested in higher dental education. In these early stages there is an opportunity for securing a uniform curriculum in all the schools that may not be available at a later period.

"Should the dental hygienist be educated in the dental college building?" This question propounded to the deans of twelve of the leading dental colleges resulted in eight affirmative and four negative replies. This is an evidence of a desire to associate the dental hygienist with the dentist even in training. By this association and environment she should acquire a respect for dentistry and all that it embraces, and should more fully appreciate her own limitations. This has been recognized by the directors of the Forsyth Infirmary. As a result of the recent affiliation with Tufts College, the school becomes the Forsyth-Tufts School for Dental Hygienists. In Rochester the university is to have a medical and dental school in conjunction with the Eastman Dispensary, thereby associating the school for the dental hygienist with the dental school.

The course of training should cover - at least one collegiate year. It would be desirable to have the state law so constructed that graduates would be compelled to serve in recogrized municipal or institutional dental infirmaries for another year before the granting of their licenses. Thus an additional period of training would be provided for, and a continuous supply of available workers for public institutions would be assured. This is successfully applied to school teaching and other callings, but would require strict supervision. Her preliminary education should consist of four years' high-school work or its equivalent, and credentials of character should be submitted before admittance. Preference should be shown those women who come from the professions of teaching or medical nursing. But excellent material may be found in the dental office, where the office assistant with creditable ambitions seeks to broaden her sphere of usefulness. The theoretical subjects should be those necessary to give her an intelligent grasp of the importance of her calling and of its relation to the work of the dentist. While I can learn of no objection to the lectures being given by members of the faculties of dental and medical schools, the efforts of at least one college to train dental hygienists in the same classes with dental students have been most unsatisfactory.

Practical work should consist of a course in tooth morphology, manual dexterity being acquired simultaneously with a knowledge of tooth form. The carving of artificial ivory blocks by hand fulfils this purpose. The operative technic on manikin heads as taught in Columbia University consists of three weeks' intensive training, with the use of porte polisher and wood points. The student is then taught instrumentation for three weeks on the manikins. When she has demonstrated the necessary aptitude she is permitted to give prophylactic treatments to patients in the infirmary, and devotes the remainder of the course to infirmary practice. As a result of this intensive training in specialized work, she emerges as a skilful, intelligent prophylactician ready to serve under the guidance of the dental practitioner. An important part of her training has been in the field of lay education. And she is prepared to give demonstrations in oral hygiene either in the office or the classroom.

Legislation.-All legislation concerning the dental hygienist should be initiated within the dental profession. As the work of these women is so closely allied to dental service, the dentist should always have legal as well as professional supervision over their activities.

Experience has proved that the legalization of the dental hygienist has furnished an invaluable aid to dentistry in- 
stead of opening the door to illegal dental practice, as so many had feared.

Prior to the passage of the dental law of 1916 in New York state, the contention was made, particularly in New York City, that these women, if their vocation was legalized, could not be restrained from performing other dental operations. Conditions in New York City had been a scandal in the eyes of the dental world because of the flourishing of the illegal dental practitioner: The cosmopolitan population, combined, with weak penalties in the law, made detection difficult and conviction no great hardship. It is hard to conceive of more unfavorable circumstances under which to introduce into the community a person legalized to give oral prophylactic treatment but restrained from doing more. But the same law that legalized the dental hygienist, defined dentistry concisely and made annual registration compulsory for both dentist and hygienist. Control over dental practice became at once immensely simplified.

In order to secure authentic data as to the possible violations of the law by dental hygienists, I communicated with the state department requesting a record of all prosecutions during the four years that the law had been in effect. I received the following reply from $\mathrm{Dr}$. Augustus S. Downing:

Albany, March 20, 1920

\section{Dear Mr. Stevenson:}

I have your letter of March 17 and beg to say in regard to your inquiry as to whether licensed dental hygienists have violated, or are violating the dental law by performing dental operations other than those permitted under the statute, that up to the present time there have been no complaints of such violation, nor have our inspectors who have been active in investigating the work of dental hygienists with a view to making report upon the efficacy of licensing them found any occasion for criticising the operation of the law.

Trained, licensed hygienists are more and more in demand for public institutions and for private dental offices, but the larger percentage of the licensed hygienists go into public service under the supervision and direction of duly licensed and qualified dentists.

There is an increasing demand both in the cities and in the rural districts for the services of trained, dental hygienists in the schools, and I am satisfied that the provision of our dental practice act authorizing the licensing of dental hygienists was wisely conceived.

Most cordially yours,

(Signed) Augustus S. Downing

Since the legalizing of dental hygienists by statute in the state of New York in 1916, Connecticut, Massachusetts, Iowa, Máine, Cólorado, Minnesota, New Hampshire, Oklahoma, Tennessee, and Michigan' have passed similar laws; legislation is now pending in Illinois, California, North Carolina, Pennsylvania, Delaware, Virginia, and Georgia. With the exception of New Hampshire, Massachusetts, Colorado, and Michigan the laws limit this field to women and there is no evidence that even in these latter states the state examiners will permit them to qualify. Some of the state laws designate them as dental hygienists, others as dental nurses, which is unfortunate, as this tends to produce confusion among the laity. Legislation as well as education for the dental hygienist should be made uniform, and is more easily accomplished in the early stages of the development of this adjunct to dentistry.

\section{The Record of the Dental}

\section{HyGIENIST}

A survey of what has been accomplished by dental hygienists in various communities is most interesting. The record of fve years' work of these dental hygienists in the schools of Bridgeport is the most forceful argument for preventive dentistry ever presented. It has been a topic of discussion among educational authorities as well as health workers thruout the country. During this period 125,950 prophylactic treatments were given to children and the latest records show that, of the 127 dental hygienists registered in Connecticut, 47 are engaged in public-school work, ケospitals, dispensaries, or factories. During the progress of the war, many hygienists volunteered their services for work in the evening, and gave 800 prophylac- 
tic treatments to men drafted into service. This is a record of which Connecticut may well be proud.

In New York state inadequate appropriation of funds has prevented the establishment of so enviable a record. The city of Rochester, aided by the Rochester Dental Dispensary, can show the best result for the state. A communication of recent date from Dr. H. J. Burkhardt reads as follows:

I could not tell you the number of prophy lactic treatments given in Rochester by dental hygienists, because until this year a considerable amount of the prophylactic work was done by dental internes employed here in the dispensary. Since January 1 the prophylactic work in the schools has been done by graduate dental hygienists and by students from the dispensary school. I expect before the first of July the dental hygienists will have done, from January to July, about 35,000 mouths. At the present time there are seventeen graduate hygienists and forty-two students at work in the schools of Rochester.

You probably will be interested to know that since I have called in the graduate dentists who have heretofore done the work, I have had fewer complaints and less trouble than at any time since the work was started here. The work of the young women and their conduct generally in the schools is very much more satisfactory than when the men were employed. I am hoping to secure enough graduates from this year's class so that in the future I shall not be obliged to use graduate dentists again to do this work

In New York City the municipality has been slow in providing funds to engage dental hygienists in the schools. As a result there are about sixty engaged in private practice with dental practitioners. Four others are in the service of the department of health; five are in the dental department of the Metropoli$\tan$ Life Insurance Company; six in the charitable organizations, a total of fifteen in all. Twenty-five members of the alumni association of Columbia University, all engaged in private practice, have volunteered at least one morning a week for service in the public schools. As many of these young women are engaged by private dentists on a time basis, the service is a most com- mendable one. The undergraduate dental hygienists have given over twelve hundred prophylactic treatments in the Italian district this year, and almost half the class have indicated their intention of entering public work after graduation, One of our graduates sacrificed an excellent position to demonstrate the value of the dental hygienist at Mount Alto in this state, in response to the call of Dr. Beck. The students in Columbia University have given over fifteen thousand prophylactic treatments to date in the Infirmary.

In Massachusetts records show but two dental hygienists doing work in charitable institutions and two in the public schools, and Dr. Harold DeWitt Cross writes that the reason for this is, that "those who are most strongly in favor of legislation for the practice of dental hygienists have done nothing to promulgate the service in public health work." This is most unfortunate, and while not conversant with the reasons, I believe that it is but a question of time that with the increasing number of graduates from the Forsyth-Tufts school there will be many more available, if the opportunity is offered. The undergraduate dental hygienists have given about 17,200 prophylactic treatments in Boston in the last three years. Statistics from the other states are not available, but it must be borne in mind that their legal enactments are so recent that organized efforts could hardly have been carried on for a sufficient length of time to permit of tabulation. I believe the total prophylactic treatments given by graduate and undergraduate dental hygienists to date would aggregate 250,000 .

\section{INDUSTRIAL Clinics}

Consideration of the field of the dental hygienist brings us to the question of the industrial clinic. The operation of the industrial dental clinic involves some problems that reach so deeply into the fundamentals of sociology that they cannot be disregarded. Whether it is con- 
ducted on a free service basis or a small fee basis is a difference of degree only. Moreover, anything that savors of paternalism is justly resented by the selfrespecting worker as an infringement upon personal privilege and independence. For this reason you cannot enforce legislation for individual health, except where the ill health of one is a source of danger to the community. While it is generally accepted by the laity as well as by the employers of labor that dentai efficiency increases industrial efficiency, there are limitations within which the efforts of the employer must be confined. The workers of today, particularly the skilled and unskilled manual laborers, are financially able to pay the fees of the private practitioner. The rapid increase in the rate of compensation of these toilers place them in a class to which even luxuries are not denied. Many have acquired means so much above their needs that they are spending with reckless abandon. By increasing instead of curtailing their hours of labor they could still further add to their income, and thereby have ample means with which to pay for proper dental service, incidentally bringing about a much-needed increase in production. The industrial worker needs not charity, but enlightenment as to his dental needs, and may then be relied upon to seek the private dentist who is prepared to give him the service he requires.

The industrial dental public clinic should be mainly educational. The employees may be given periodic prophylactic treatments and instruction in oral hygiene; the general dental service could be performed elsewhere. The clinic may also provide emergency treatment. I can conceive of isolated manufacturing or mining plants, such as the Colorado Fuel and Iron Company at Pueblo, Colorado, probably giving all types of dental service, since their inaccessible location prevents employees and their families from securing dental service otherwise. The same does not apply to those plants located in urban communities and companies assume a tremendous responsibility in operating general dental clinics in these places.

Can real dental service, worthy of the name, be secured from dental operators in these clinics as they are at present conducted? Most of the operators are young and inexperienced, and consider their position to be of a temporary nature. The very system of appointment and lack of prospects for future advancement discourage their best efforts. Urless all posts are carefully graded and well paid there is no incentive to give high-grade service.

I would particularly emphasize the menace of dental diagnostic work as carried on in some industrial clinics where there is no fixed responsibility. The taking and interpreting of dental radiographs requires diagnostic ability acquired only by experience, and is too important a phase of dental service to be performed at these clinics. It was to prevent irresponsible dental work that the law of New York state was amended, forbidding corporations to practice dentistry. So in our zeal for public service we should not indorse a return to another form of corporation dentistry with its old abuses.

Experience has shown the excellent results which can be obtained thru the program of preventive dentistry where the clinic is confined to oral prophylactic and emergency treatment.

A well-regulated industrial clinic devoted to the purposes stated above can, in addition to increasing the efficiency of the worker, become a forceful factor for health in a community. Such clinics deserve the heartiest support of every member of the dental profession.

\section{CoNClusion}

I made the statement at the beginning of my paper that dentistry was passing thru a critical period. I am most optimistic as to the outcome, and believe it will emerge a more glorified profession 
and will command the respect that the guardians of oral health deserve. In the meanwhile, the individual practitioner must keep pace and not mark time, nor must he be blinded by tradition or prejudice. This paper has touched upon only one of the phases of this necessary progression. By way of summing up, permit me to submit to you the following:

1. The dentist as the guardian of the oral health of the community can no longer disregard preventive measures as a part of daily practice.

2. The ravages of dental caries should be minimized by systematic oral prophylaxis under the direction of the dentist. distribution of her labor will ultimately be adjusted by the law of supply and demand.

6. The dental hygienist is an important factor in the progress of dentistry and the elevation of her service is a matter of concern to the dental profession.

7. It devolves upon the dental societies to propose appropriate legislation legalizing the dental hygienist in every state in the Union, as all such legislation should be initiated by the dental profession.

As an appendix, permit me also to present in outline form what I conceive to be the field of the dental hygienist.

THE FIELD OF THE DENTAI, HYGIENIST

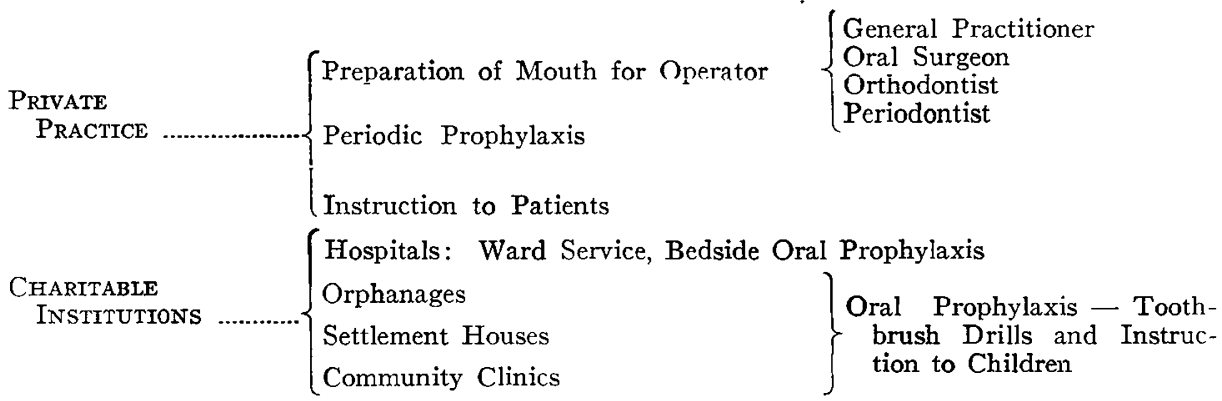

Health Centers: Co-Operation With Public Health Nurse

Schools ……............... $\left\{\begin{array}{l}\text { Public Schools } \\ \text { Parochial Schools } \\ \text { Private Schools }\end{array}\right\} \begin{aligned} & \text { Examination of Children, } \\ & \text { Prophylactic Treatments, } \\ & \text { Instruction in Oral Hy- } \\ & \text { giene }\end{aligned}$

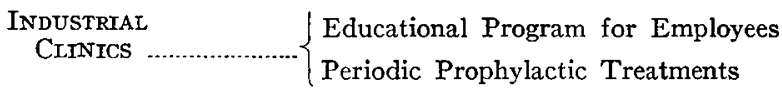

3. If the burden of professional duties prevent the dentist from giving this service to his patient he should provide adequate care in this field.

4. The dental hygienist should be properly trained and her activities be regulated by law. Where she has been given opportunity she has met all expectations.

5. Whether she serves in a private office or in public institutions she is rendering humanitarian service. The

\section{DISCUSSION}

Alfred C. Fones, Bridgeport, Connecticut: In the prevention of dental caries the great factors are education, dietetics, and cleanliness. In order to create interest in education and dietetics, we start on the simple process of cleanliness. We find that when children have clean teeth and realize the sensation of a clean, wholesome mouth, they become interested in mouth hygiene. And after they have had a little education on the general topics of hygiene, they are willing to consider your arguments as to what they should eat, even to the giving up of refined sugar.

The most difficult thing is to get a message into the homes, and have it carry any weight. 
The seeping of such knowledge into the minds of the parents means years and years of work. If we were all agreed, as a man, upon some definite process to be followed to bring about the results we are striving for, it would still take years to accomplish it. The only way to get at it is thru a generation of education in our public schools. We are all set in our habits even with the intelligence which we may have. But children can be taught good habits for in the public schools the hygienist becomes a teacher, and as a teacher her word becomes law to the children. And that word is carried home, many times, possibly, with more influence than we realize.

It is slow work, but it is coming. I remember when we first started in school work that only about ten children in one hundred were brushing their teeth daily. Now we do not find ten children to one hundred who, when entering school in the first grade, do not own a toothbrush. Why? Because brother and sister have taught them that they must have a toothbrush, and they bring money, not only for brushes for the littler ones at home, but also for mother and father and for sister and brother who are working. We sell them at cost and are glad to do so.

Dr. Stevenson presented the main issues of dental hygiene, the main issues for those who have been doubtful as to the necessity for the dental hygienist. The arguments are convincing, even to the skeptical.

I am presenting our sixth annual report of the work of the dental hygienists in the public and parochial schools of Bridgeport, for the year ending 1920.

A year ago I published a report of our findings for five years and the comparison of the statistical children of the fifth grade with those of the control class taken five years previously. Possibly some of you have read that report. This sixth-year report merely emphasizes the splendid work these hygienists are doing and is, I consider, an added argument to Dr. Stevenson's paper:

"The Division of Dental Hygiene submits the sixth annual report of the educational and preventive dental clinic in the public and parochial schools, from September 10, 1919, to June 25, 1920, inclusive of the summer clinic of 1919.

"The dental corps comprised twenty-one dental hygienists (one on half-time), two supervisors, and an assistant supervisor, who are also dental hygienists, and three women dentists.

"In the years previous to the petition of the parochial school to be included in our clinic, a corps of twenty dental hygienists was required to provide adequate prophylactic service for the children of the first five grades of the public schools. Six additional hygienists were needed to extend this service to the parochial schools, and altho we were able to secure these workers in 1918, our corps has been gradually depleted, and the lack of a training school for dental hygienists in Connecticut has made it impossible to secure more hygienists.

"In spite of this unfortunate situation the children of the parochial schools each received one prophylactic treatment this year.

"Total number of individual children receiving prophylactic treatments.

"Total number of prophylactic treatments given. 20,918

"The supervisors and dental hygienists,

"The supervisors and dental hygienists gave instructions in the home care of the mouth by means of toothbrush drills and classroom talks to 22,587 children. The children purchased 10,235 brushes, and many more brushes could have been sold if it had been possible to secure them. Every child is required to have a toothbrush, and an evidence of the increasing interest in mouth hygiene is the willingness of parents and children to pay for the brushes. Only 543 brushes were given away this year, a reduction of 931 from last year.

"It is our aim to gradually increase the general educational field of the hygienist in the classroom, especially as regards correct diet, and during the past year two dental hygienists have spent considerable time in the second to the fifth grades giving a series of practical food talks. At the completion of these talks the fifth-grade children prepared original menus for one day, covering the food requirements of the body. This education was given to 7,190 children. In fact, practically all the educational work for the year was centered on foods, and the pamphlets and lectures with lantern slides given by the supervisors and school dentists to 10,613 children dealt with correct diet and the need for restricting the use of free sugar. The mouth as the important factor in the spreading of communicable disease, such as influenza, was also a lecture subject.

"The efforts of our three women dentists are concentrated chiefly upon the safeguarding of the first permanent molars of the children of the first and second grades.

"The results of this important service is shown by the following: In 1915 the examination of the first permanent molars of the fifth-grade control class showed that 15.1 per cent of these molars had been lost. Our records this year show that but 7 per cent of the first permanent molars have been lost-a saving of over 50 per cent more molars as a result of the filling of the fissure cavities when these children were in the first or second grades, and the teeth had just erupted.

Total number of individual children hav-

ing teeth filled. 889

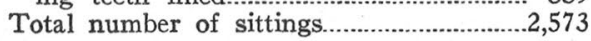


Total number of first-grade children worked for.

Total number of second-grade children worked for..

Total number of third-grade children worked for.

Total number of fourth-grade children worked for.

Total number of alloy fillings in permanent molars

Total number of molars filled. $. .4,566$

Number of treatments for the relief of pain

Number of extractions of loose deciduous teeth

Number of treatments for children above second grade.

Number of extractions of abscessed deciduous teeth.

"The extraction of a large number of $a b-$ scessed deciduous teeth marked a new proce-
"Following is a table of the record of indi37 vidual schools

"The children passing into the sixth grade are out of the general supervision of the hygienists, and due to our rapidly increasing population many hundreds of these children were newcomers in the past two or three years and therefore are not statistical children. In order to send as many of them as possible into the sixth-grade with clean mouths and sound teeth, a prize was offered to any pupil in the fifth-grade who at the last examination would present a clean mouth with no cavities in the permanent teeth. There were 551 children who passed this examination and received prizes. It must be considered that these children went to a dentist of their own initiative to have the permanent teeth placed in a sound condition, and had also kept their mouths clean from food debris by systematic brushing.

PERCENTAGE OF REDUCTION OF DENTAL CARIES IN PERMANENT TEETH OF STATISTICAL CHILDREN

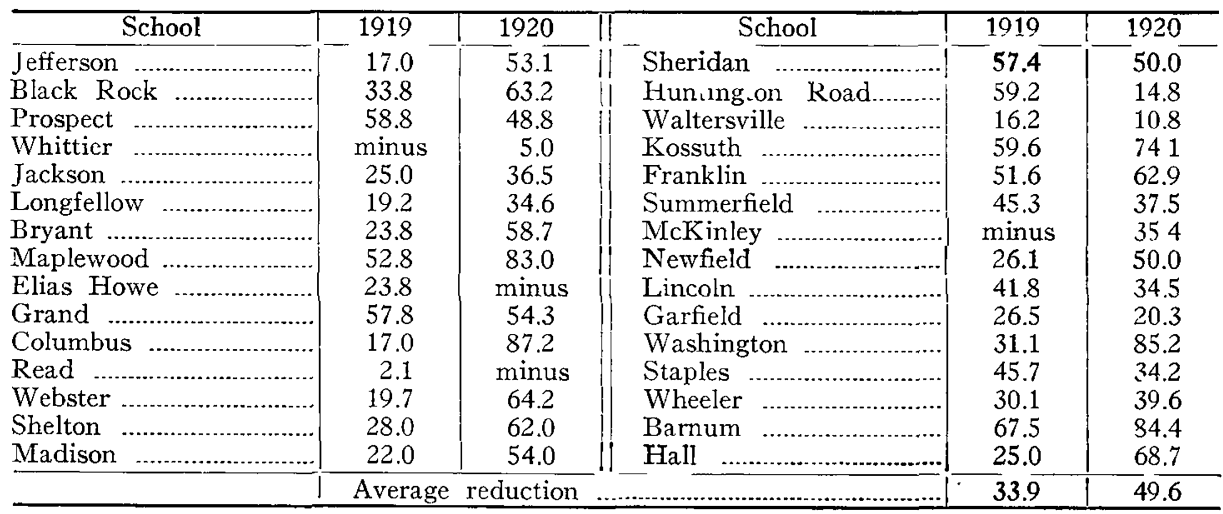

dure this year, this service being provided for any child up to the fifth grade in order to remove, as far as possible, any dental condition that would be a menace to the child's health.

"The report of last year [1919] completed a five-year demonstration of this type of educational and preventive clinic and showed very gratifying results. The present report 11920] will be based upon the data of the condition of the mouths of those children who have had five years oi prophylactic treatment and education, but have had no general operative work provided for them.

"In 1919 the average reduction of dental caries in the permanent teeth in thirty schools was 33.9 per cent in a five-year period as compared with the control class. A similar comparison for 1920 shows a reduction of 49.6 per cent dental caries in the permanent teeth.
"Only thru education and an appreciation of the importance of sound teeth could these children have been induced to go to the dentist in such numbers, for altho the prize was an incentive, it would not attract the average child sufficiently to undergo a dental operation to secure it. In other words, the result of systematic education was that these children upon their own responsibility sought dental service and maintained clean mouths by faithful brushing, developing what might be termed a dental conscience."

Everyone knows that it is insanitary to spit on the sidewalk; we know the dangers of the expectorations from the mouth, and yet how many of us have a sanitary conscience and will not spit on the sidewalk?

"We believe this record makes a favorable contrast to a general repair clinic where the mouths of children are put in good condition 
because those in charge know the importance of it. To the child it is too liable to mean merely an operative ordeal, and owing to the lack of education and appreciation of sound teeth the child fails to keep the mouth in good condition.

"In connection with this discussion it has been thought interesting to give in detail the condition of the mouths of our fifth-grade children as a whole, irrespective of statistical children in comparison with the data of the control class of 1915 . the number of children with whom she comes in contact and works for enables her to remember the mouths of individual children and to give special help in cases which need it. Her constant presence in the school is a daily reminder of clean mouths and sound teeth to all the pupils and teachers in her school. She is able to carry thru lively competition between rooms for the reward of clean teeth banners. honor rolls, etc. Her undivided interest in the children of one school brings her in touch

\begin{tabular}{|c|c|c|c|c|c|c|c|c|c|c|c|c|c|c|}
\hline \multirow{2}{*}{ Year } & \multirow{2}{*}{ 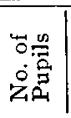 } & \multirow{2}{*}{ 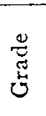 } & \multicolumn{2}{|c|}{ State of Health } & \multicolumn{3}{|c|}{ Color of Gums } & \multirow[t]{2}{*}{$\begin{array}{c}\text { Fis- } \\
\text { tulas } \\
\end{array}$} & \multirow[t]{2}{*}{$\begin{array}{l}\text { Maloc- } \\
\text { clusion }\end{array}$} & \multicolumn{3}{|c|}{ Use of Toothbrush } & \multicolumn{2}{|c|}{ Cavities } \\
\hline & & & Clean'Fair & Dirty & $\mid \begin{array}{c}\text { Dark } \\
\text { Red }\end{array}$ & $\begin{array}{l}\text { Light } \\
\text { Red }\end{array}$ & Pink & & & naily' & $\begin{array}{l}\text { Occa- } \\
\text { innally }\end{array}$ & $\begin{array}{l}\text { Not } \\
\text { Usert }\end{array}$ & $\left|\begin{array}{c}\text { Tempo } \\
\text { rarv }\end{array}\right|$ & $\begin{array}{c}\text { Perma- } \\
\text { nent }\end{array}$ \\
\hline $\begin{array}{l}1915 \\
1920 \\
\end{array}$ & $\begin{array}{l}1946 \\
2313\end{array}$ & $\begin{array}{l}5 \\
5 \\
\end{array}$ & \begin{tabular}{|r|r|}
77 & 658 \\
1105 & 1005 \\
\end{tabular} & $\begin{array}{r}1211 \\
203 \\
\end{array}$ & $\begin{array}{l}581 \\
126 \\
\end{array}$ & $\begin{array}{l}1244 \\
1361\end{array}$ & $\begin{array}{l}121 \\
826 \\
\end{array}$ & $\begin{array}{r}142 \\
92 \\
\end{array}$ & $\begin{array}{l}1867 \\
2294 \\
\end{array}$ & $\begin{array}{r}307 \\
1381\end{array}$ & $\begin{array}{r}1060 \\
852 \\
\end{array}$ & $\begin{array}{r}579 \\
80 \\
\end{array}$ & \begin{tabular}{|l|}
2006 \\
3266 \\
\end{tabular} & $\begin{array}{r}10726 \\
7393 \\
\end{array}$ \\
\hline
\end{tabular}

"We find upon careful examination of the permanent teeth that this year the entire fifth grade averaged but 3.2 cavities per child in contrast to 5.5 cavities six years ago. It is interesting to note the general improvement in the mouths of these children, many of whom have been in our school system but a comparatively short time.

\section{General Comments}

"The splendid results which are being accomplished in mouth hygiene for the children in our schools have been largely due to an efficient and loyal corps. The dental hygienist evidently recognizes and appreciates her great field of service in public health work, for we have had but two cases of members of our corps leaving for work in private offices.

"This is a noteworthy record and proves conclusively the interest of women in this work, for, unfortunately, in Connecticut we have had no training school for hygienists since 1917, and altho the value of dental prophylaxis in private offices has been increasingly recognized, our corps has remained loyal to public health work over a period of six years.

"Previous to September, 1919, the school work was handled entirely by a traveling corps of hygienists with portable equipments. The corps remaincd in a school until the work was completed and then moved to the next school, returning at a later period. The interest in mouth hygiene in the intervals between the visits of the hygienists depended in a great measure upon the influence of teachers.

"In September, 1919, we placed a resident hygienist in certain schools and a comparison of the records with those of the traveling corps indicates that this procedure would be ideal if sufficient hygienists could be secured.

"We intend this year to locate as many resident hygienists as can be spared from the traveling corps. A few of the many advantages of this plan are as follows: A reduction of with the parents who are frequent visitors at her clinic.

"It is apparent that the improvement in any school depends materially upon the co-operation of principals and teachers with the hygienists and our records will show how heartily this help has been given. The personal attitude of the teacher means much to the child, and it is invariably true that the best records come from the room of the teacher who has an appreciation of mouth hygiene. This is forcefully illustrated in the case of the McKinley School, which had a minus record for 1919. The determination of the individual teachers to aid the hygienist in improving the record of this school included competition in daily brushing which resulted in five rooms of 100 per cent dividing the banner for one semester, one of the five having a record of 100 per cent for the entire year."

This means that every child in that room from September to June never failed once in the brushing of his teeth, mornings, and afternoons before he came to school, which we think is a wonderful record and a gratifying response to the teacher's efforts. In addition to this seventy fifth-grade children out of one hundred were prize children for clean mouths and sound permanent teeth, and the statistical children showed a reduction of 35.4 per cent in dental caries.

Many other evidences of intelligent co-operation in other schools could be mentioned. This report is only one evidence of the excellent service rendered by the dental hygienists. This great cause of prevention is limited only by an inadequate supply, at the present time, of women educated and trained as dental hygienists. The future looks very bright, however, as training schools are on the increase, and eventually I hope to see one established in every state, for the need in each state is so great that it must be supplied in this way. 